\title{
Using intranasal corticosteroids
}

\author{
James Fowler MD, Leigh J Sowerby MD
}

Cite as: CMAJ 2021 January 11;193:E47. doi: 10.1503/cmaj.201266

\section{Intranasal corticosteroids can be used as primary or \\ 1 adjunct therapy for many inflammatory conditions within the nasal cavity \\ About $5 \%$ of Canadians are affected by sinonasal inflammation. ${ }^{1}$ There is broad expert consensus supporting the effectiveness of intranasal corti- costeroids for treating allergic and nonallergic rhinitis, acute rhinosinus- itis and chronic rhinosinusitis with and without nasal polyposis., ${ }^{2,3}$}

\section{There are 9 intranasal corticosteroids approved in Canada, all with similar efficacy}

Intranasal corticosteroids affect both early and late inflammatory responses by inhibiting the production of proinflammatory cytokines, inflammatory enzymes, lymphocyte proliferation and delayed hypersensitivity. ${ }^{2,3}$ Although efficacy is similar across different corticosteroids, ${ }^{2}$ certain types have specific indications (Appendix 1 , available at www.cmaj.ca/lookup/doi/10.1503/cmaj.201266/tab-related-content).

\section{3}

\section{Intranasal corticosteroids are safe, but local adverse effects are common}

One in 10 patients have local adverse effects, including burning or stinging, dryness and epistaxis. ${ }^{2}$ Systemic adverse effects are very uncommon, and there is no correlation with use and hypothalamic-pituitary-adrenal suppression or increased intraocular pressure. ${ }^{4}$ One study linked beclomethasone dipropionate to decreased growth velocity in children, ${ }^{4}$ but no association has been found for other intranasal corticosteroids. For patients on concurrent oral and inhaled steroids, there is a theoretical increased risk for systemic side effects; therefore, a second-generation steroid spray with low bioavailability is suggested (Appendix 1). ${ }^{5}$

\section{Correct administration of intranasal corticosteroids is crucial for desired therapeutic effect}

Providers should show patients how to direct the intranasal applicator away from the nasal septum. This can be achieved by using the contralateral hand for steroid application (Figure 1). Proper technique will reduce local adverse effects and increase adherence. Daily use for 8-12 weeks is often required for full therapeutic benefit, but adherence can be affected by cost (Appendix 1).

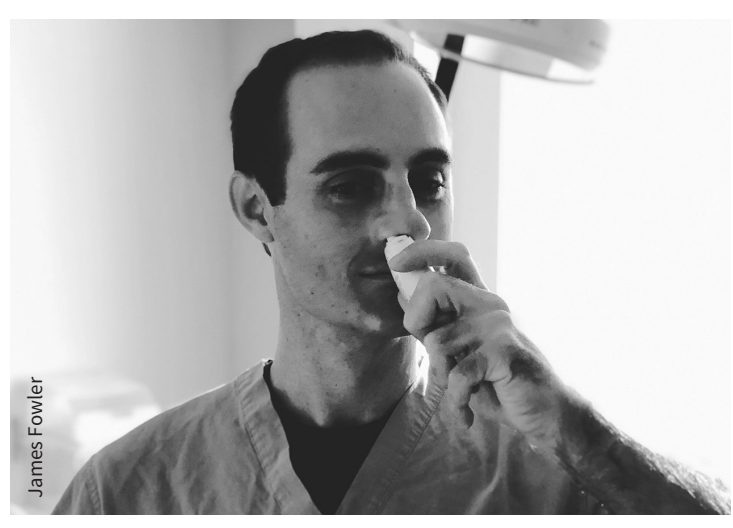

Figure 1: Photograph of the author (L.J.S.) showing the contralateral hand technique for applying intranasal corticosteroid.

\section{5}

Fewer intranasal corticosteroids are available for children and pregnant women For children, mometasone furoate ( $\geq 3 \mathrm{yr}$ ), fluticasone propionate $(\geq 4 \mathrm{yr})$, triamcinolone acetonide $(\geq 4 \mathrm{yr})$ and ciclesonide ( $\geq 6 \mathrm{yr}$ ) are currently approved. ${ }^{2}$ Budesonide is the only intranasal corticosteroid with established safety in pregnancy. ${ }^{6}$

\section{References}

1. Kaplan A. Canadian guidelines for chronic rhinosinusitis: clinical summary. Can Fam Physician 2013;59:1275-81.

2. Wise SK, Lin SY, Toskala E, et al. International consensus statement on allergy and rhinology: allergic rhinitis. Int Forum Allergy Rhinol 2018;8:108-352.

3. Orlandi RR, Kingdom TT, Hwang PH, et al. International consensus statement on allergy and rhinology: rhinosinusitis. Int Forum Allergy Rhinol 2016;6:S22-209.

4. Gupta R, Fonacier LS. Adverse effects of nonsystemic steroids (inhaled, intranasal, and cutaneous): a review of the literature and suggested monitoring tool. Curr Allergy Asthma Rep 2016;16:44.

5. Juniper EF, Ståhl E, Doty RL, et al. Clinical outcomes and adverse effect monitoring in allergic rhinitis. J Allergy Clin Immunol 2005;115(Suppl 1):S390-413.

6. Alhussien AH, Alhedaithy RA, Alsaleh SA. Safety of intranasal corticosteroid sprays during pregnancy: an updated review. Eur Arch Otorhinolaryngol 2018;275:325-33.
Competing interests: Leigh Sowerby reports receiving personal fees from Mylan, GSK and Sanofi, and grants from GSK, Roche and AstraZeneca, outside of the submitted work. No other competing interests were declared.

This article has been peer reviewed.

Affiliation: Department of Otolaryngology-Head and Neck Surgery, Western University, London, Ont.
Content licence: This is an Open Access article distributed in accordance with the terms of the Creative Commons Attribution (CC BY-NC-ND 4.0) licence, which permits use, distribution and reproduction in any medium, provided that the original publication is properly cited, the use is noncommercial (i.e., research or educational use), and no modifications or adaptations are made. See: https://creativecommons.org/licenses/by-nc-nd/4.0/

Correspondence to: Leigh Sowerby, Leigh.Sowerby@sjhc.london.on.ca 